Another and perhaps no less significant feature of the report is the reference to land development following the winning of the peat. The depopulation of the Highlands may be attributed to the existence of barren areas, costly in the maintenance of social services more abundant in other parts of Britain. The conversion of the peat areas to agricultural use and afforestation requires, beyond the winning of the peat, intensive drainage, the cultivation of arable and pastoral soil conditions, and the features necessary for the planting of trees, namely, a suitable subsoil and absence of exposure to wind. Thus the Forestry Commission estimates that planting an area of twenty thousand acres might employ ultimately six hundred persons when the forest is in full production.

Thus may be seen the potentialities of a hitherto neglected site of natural resources as affected by the march of science and engineering.

R. J. SARJANT

\section{CHEMICAL INDUSTRY IN BRITAIN DURING 1953}

$\mathrm{S}$ UPPLEMENTING the report on the chemical industry, 1949, published in February 1950, the Association of British Chemical Manufacturers has now issued a "Report on the Chemical Industry, 1953"*, based on replies received to a questionnaire addressed to its members early in 1953. The present report adopts the same definition of chemical industry as was used in the earlier one: "the manufacture of heavy chemicals, industrial gases, fertilisers, dyestuffs, medicinal and other fine chemicals, explosives, plastics and synthetic resins, but not the compounding of chemicals to make such products as paints, insecticides, sheep and cattle dips, and pharmaceutical preparations". On this basis the industry represents about one-third of the activities covered by the definition of chemicals and allied trades used by the Ministry of Labour and National Service for its statistics.

For 1952, returns were received from 234 of the 272 firms that previously reported for 1948 , and these 234 firms employed capital of $£ 406 \cdot 8$ million, compared with $£ 230 \cdot 6$ million in 1948 , the capital of the

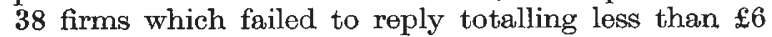
million. The total staff employed in the industry increased from 141,817 to 151,349 , the scientific staff rising from 6,176 to 7,406 , or roughly 20 per cent, compared with the forecast of an increase of 40 per cent in respect of chemists, by 1953, in the earlier report. Employed capital per employee rose from $£ 1,600$ to nearly $£ 2,700$ at the end of 1952 , when the expansion schemes in progress involved a total capital expenditure of $£ 138$ million, with additional schemes awaiting licences or under consideration to the total of $£ 91$ million. The expenditure of $£ 11 \cdot 2$ million on research and development in 1952 approximates closely to the forecast of 32 per cent increase in 1948 , but the number employed on research and development only rose by 8 per cent, from 10,100 to 10,914 ; in the same period the number of scientific workers so employed rose from 3,000 to 3,267 . When the additional laboratories and other experimental facilities, for which capital expenditure of $£ 6 \cdot 2$

- Association of British Chemical Manufacturers. Report on the Chemical Industry, 1953 ; a Supplement to the 1949 Report. Pp. 12.
(London: Association of British Chemical Manufacturers, 1954.) $1 \mathrm{~s}$. million is in hand, are available, recurrent expenditure on research and development will rise to $£ 12 \cdot 7$ million or almost 50 per cent above that in 1948 .

New products are being added to the industry's selling range at the rate of several hundred every year, and production has increased by 29 per cent in volume, compared with 15 per cent for all manufacturing industries, with an estimated increase in value of 60 per cent. Productivity increased by 21 per cent on a volume basis and 51 per cent on a value basis, these figures being attributed to the increase in employed capital, the increasing use of instrumentation for process control and the application of work study methods. Nevertheless, it has not been possible, nor will it ever be, to eliminate imports ; of the $£ 49.68$ million imported in $1952, £ 9.3$ million consisted of potassium compounds and extracts for tanning, for which there is no available indigenous supply of raw materials. Drugs, medicines and medicinal preparations were imported to the amount of $£ 4.54$ million, cellulose acetate to $£ 2 \cdot 38$ million, sodium compounds to $£ 2.97$ million, vinyl resins to $£ 1.19$ million and synthetic organic dyestuffs to

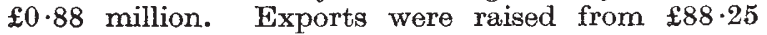
million in 1948 to $£ 151.7$ million in 1952 ( $£ 146$ million in 1953) with indirect exports of chemicals estimated at $£ 60$ million in 1952 , the United States of America ( $£ 11.07$ million) and India ( $£ 10.9$ million) being the largest markets. Exports to all dollar markets rose from $£ 5.62$ million in 1948 to $£ 19.05$ million in 1952.

The difficulties referred to in the earlier report in the execution of the industry's expansion schemes still exist, though they are less serious. It is much easier to obtain the necessary authorization for a new project, and the sulphur position has been eased. The scarcity of scientific and technical staff still hampers the development of the industry and its efforts to increase productivity, and the rising costs of fuel and transport are seriously affecting the competitive position of the chemical industry and other branches of British industry in the export market. The report claims that there is every prospect that the industry will continue to hold its own and expand its exports, more particularly the specialities being developed by research. The industry is also confident of its ability both to meet the new requirements of Britain's consuming industries, with their changing technologies, and to provide for the changing demands in the overseas markets where industrialization is taking place.

\section{RECENT ADVANCES IN THE CHEMISTRY AND BIOLOGY OF THE PTERIDINES \\ SYMPOSIUM IN LONDON}

A SYMPOSIUM sponsored by the Ciba Foundation, the twenty-fifth of its kind, was held in London during March 22-25, bringing together for the second time chemists and biologists working in the pteridine field. The programme of the symposium gave equal weight to discussions upon the chemical and upon the biological aspects of pteridine research, the former being held under the chairmanship of Prof. A. Albert, of the Australian National 
University (Dept. of Medical Chemistry, 183 Euston Road, London, N.W.1), and the latter under that of Dr. W. Jacobson (Strangeways Research Laboratory, Cambridge).

In a series of three papers, Dr. E. C. Taylor, jun. (University of Illinois, Urbana), covered the work of his school upon the degradation and synthesis of the polysubstituted pteridines, and upon the elucidation of the structure of some pyrimido-pteridines. Pteridines substituted in both the 2-and the 4-positions by amino- or hydroxy-groups undergo ring opening on aminolysis to give 2-amino-3-carbamidopyrazines, compounds which, Dr. Taylor indicated, are of particular utility in the synthesis of pteridines with substituents in the pyrimidine ring different from those of the compound degraded. Another important intermediate is $2: 4: 6: 7$-tetrachloropteridine, which can be reduced to $2: 4$-dichloro-5:6:7:8-tetrahydropteridine and to $5: 6: 7: 8$-tetrahydropteridine, and which forms $2: 4$-dichloro-6:7-diaminopteridine and then tetra-aminopteridine on treatment with ammonia. Dealing with the 'bis-alloxazine' of Wieland, Dr. Taylor reported that degradative studies show it to be a pyrimido-(5:4:6:7)-pteridine, and that such compounds can be obtained generally by the reaction between $\approx_{0} 4: 5$-diaminopyrimidine and alloxan in acid solution. Dr. G. H. Hitchings (Wellcome Research Laboratories, New York) described the preparation of two tetra-aminopyrimidopteridines by aeration of a solution of $2: 4: 5: 6$-tetra-aminopyrimidine. The predominant yellow isomer on deamination by nitrous acid gives $2: 4: 5: 7$-tetrahydroxypyrimido - $(5: 4: 6: 7)$-pteridine (Wieland's bis-alloxazine), the structure of which has been established by an unequivocal synthesis. Mr. G. M. Timmis (Chester Beatty Research Institute, London) gave an account of further condensed ring systems containing the pteridine nucleus, and of de-azapteridines and de-aza-purines, which have been obtained from the ortho-aminonitroso compounds of the benzene, naphthalene, pyridine and pyrimidine series.

Discussing the monosubstituted pteridines, of which some forty are now known, Dr. D. J. Brown (Australian National University, London) indicated that the study of these compounds has given information which is an important complement to that derived from the investigation of the natural and more complicated pteridines, while the simplicity of the compounds facilitates the study of the relation. ships between their structure and biological activities. In general, the monosubstituted pteridines can be divided into two classes: those substituted by hydrogen-bonding groups, and those containing groups which do not give rise to intermolecular binding. The compounds of the first class are soluble only in boiling water, are stable and possess high melting or decomposition points, while those of the second class are appreciably soluble in organic solvents, are relatively unstable and melt below $200^{\circ} \mathrm{C}$.

Three unresolved problems encountered in the study of monosubstituted pteridines were discussed by Prof. Albert. The first concerns the anomalous base-weakening effect of a methyl-group placed in the 4- or the 7-position of the pteridine nucleus; the second has to do with the nature of the coloured products formed by treating 2 -monosubstituted pteridines with mineral acid; and the third is the question of the structural forms of 6-hydroxypteridine involved in the slow tautomerism which is revealed by titration with alkali followed by back-titration with acid.

Dr. H. C. S. Wood (Royal 'Technical College, Glasgow) reported that the alkylation of 4- and 7-hydroxypteridine leads to $\mathrm{N}$-alkyl-pteridones, the constitution of which has been established by degradative studies followed by unambiguous syntheses. Similarly, 2:4-dihydroxypteridine gives 1:3-dimethyl-2:4-pteridone on treatment with methyl sulphate, but, as yet, the attempted alkylation of 2- and 6-hydroxypteridine has not been successful. The ultra-violet absorption spectra of the monosubstituted pteridines was discussed by Dr. S. F. Mason (Australian National University, London). Comparisons between the spectra of the hydroxy-and methoxy-pteridines and the available $\mathrm{N}$-methylpteridones suggest that the hydroxypteridines normally exist in the pteridone form, while the spectra of the amino- and dimethylamino-pteridines indicate that the aminopteridines exist in the true amino form.

Dr. G. B. Elion (Wellcome Research Laboratories, New York) described the preparation and properties of 7-pteridones substituted in the 8-position with a hydroxyethyl-group, compounds which had been prepared because of the possibility that pteridines may occur in Nature as 8-substituted sugar derivatives, analogous to the purine nucleosides. The yellow pigment isolated from the sepia mutant of Drosophila melanogaster, which was discussed by Dr. H. S. Forrest (California Institute of Technology, Pasadena), may be an 8-substituted pteridine derivative. Degradative experiments have established that the major portion of the yellow pigment is 2-amino-4-hydroxy-6-carboxypteridine and that, with a fair degree of certainty, the remaining part is a lactyl group.

Prof. M. Polonovski (Faculty of Medicine, Paris) gave an account of the isolation of the pigments xanthopterin, leucopterin and isoxanthopterin, from the organs of various insects, such as Gonopteryx and Bombyx, by means of chromatography. Dr. R. G. Busnel (Laboratory of Acoustic Physiology, Jouyen-Josas) suggested that these pigments are the end-products of the catabolism of folic acid-like precursors, as they are always accompanied by mixtures of blue fluorescent substances akin to pteroylglutamic acid in the wing scales of the Lepidoptera. In the metabolically active cells of Bombyx mori, pteridines of the isoxanthopterin type, notably fluorescyanine, are found much more frequently than derivatives of the xanthopterin type; indeed, the presence of fluorescyanine has been demonstrated, by electrophoresis and chromatography, in the ovule and the egg of the insect, and in the chrysalis at successive stages of histolysis, histogenesis and immediately after eclosion. The fluorescyanine isolated by Prof. Polonovski and Dr. Busnel was shown by Dr. F. Korte (State Chemical Institute, Hamburg) to be a mixture of isoxanthopterin and a small amount of a substance believed, on degradative evidence, to be 2-amino-4:7-dihydroxy-6- $(\alpha: \beta$ dihydroxyethyl)pteridine. However, synthesis of the compound of this structure showed complete lack of identity with the minor constituent of fluorescyanine. Attempts to elucidate the constitution of urothione, a sulphur-containing pteridine isolated from urine, were described by Prof. R. Tschesche (State Chemical Institute, Hamburg). The present evidence of degradative and synthetic experiments, together with spectral data, suggest that urothione consists 
of a dihydrothienyl-(2:3:6:7)-pteridine nucleus substituted in the dihydrothiophen ring with a glycol and a methylthio-group, and in the pteridine ring with a 2-amino-and a 4-hydroxy-group.

Dr. D. B. Cosulich (American Cyanamid Co., New Jersey) gave an account of the synthesis of a series of 2-sulphonamido-4-hydroxypteridines, compounds which had been prepared with the view of combining the biological activities of the pteridines and the sulphonamides. Neither these compounds, nor a series of pteroic acid analogues in which the benzoic acid group had been replaced by benzenesulphonamide groupings, displayed important biological activity. The $2: 4$-diaminopteridines, substituted in the 6- and 7-positions with alkyl or aryl groups, were reported by Dr. H. O. J. Collier (Allen and Hanburys, Ltd., Herts) to antagonize citrovorum factor and to do so competitively over a limited range of concentrations. It was suggested that this property is the basis of the other biological actions of the 2:4-diaminopteridines, namely, the antagonism of pteroylglutamic acid, synergism with sulphonamides, inhibition of the growth of Streptococcus and other micro-organisms in culture, suppression of infections of these organisms in laboratory animals, and crossresistance with proguanil and pyrimethamine. However, Dr. Hitchings pointed out that in lactobacilli 2:4-diaminopyrimidines and condensed systems containing the 2:4-diaminopyrimidine moiety (including 2:4-diaminopteridines) inhibit growth by interfering with an earlier stage, namely, the conversion of pteroylglutamic acid into the citrovorum factor. Antithymines and antipurines, such as 5-bromouracil and 8-azaguanine, respectively, markedly potentiate the antifolic acid activities of these compounds, suggesting that the latter interfere also with the synthesis of thymine and purines. Dr. D. J. Hutchison (Memorial Center for Cancer and Allied Diseases, New York) reported that the formation of citrovorum factor from pteroylglutamic acid is inhibited in Streptococcus by amethopterin, and that a mutant strain has been produced which is resistant to such antagonists. The growth of the mutant strain is greatly stimulated by natural purines and is inhibited by 6-mercaptopurine, a compound effecting a metabolic interference different from that of the folic acid antagonists.

Discussing the metabolic relationships between $p$-aminobenzoic acid and folic acid in micro-organisms, Dr. D. D. Woods (Biochemistry Department, Oxford) indicated that folic acid does not render all organisms insensitive to sulphonamides, nor does it invariably replace $p$-aminobenzoic acid in promoting the growth of organisms requiring the latter. Thus it is possible that none of the established forms of folic acid is a direct intermediate on the metabolic pathway from $p$-aminobenzoic acid to coenzyme $\mathrm{F}$, and that $\operatorname{som} \theta$ organisms are able to convert known forms to intermediates on this pathway, while others can do so only at a low efficiency or not at all. Dr. R. H. Nimmo-Smith (Biochemistry Department, Oxford) discussed the function of folic acid in the biosynthesis of purine derivatives, suggesting that folic acid is involved in the introduction of the $\mathrm{C}_{2}$, and perhaps the $\mathrm{C}_{8}$, atom of the purine skeleton. The suggestion was based upon the observations that the riboside of 4-amino-5-carboxamidoimidazole accumulates under conditions where the microbiological synthesis of folic acid is deficient, and that purines have a 'sparing" effect upon the concentration of folic acid needed to support the full growth of micro-organisms requiring this factor. Moreover, the free carboxamide supports the growth of a variety of micro-organisms possessing a nutritional requirement for purines, while labelled carboxamide gives rise to labelled adenine and other purines in both micro-organisms and mammals. In discussion, Dr. Hitchings described Greenberg's recent work which shows that folinic acid with carbon-14 in the formyl group, when converted into an active form by pigeon liver or by adenosine triphosphate, quantitatively transferred the radioactive carbon to the 2-position of the purine skeleton, even in the presence of excess non-labelled formate.

Dr. M. Webb (Strangeways Research Laboratory, Cambridge) reported that folic acid antagonists retard the growth of micro-organisms and give rise to populations composed of filamentous cells which are depleted of deoxyribonucleic acid. The addition of thymine with the antagonist to the growth medium prevents the formation of filamentous cells and restores the cell deoxyribonucleic acid level to normal. It seems, therefore, that folic acid antagonists decrease the rate of deoxyribonucleic acid synthesis in micro-organisms, and so inhibit the division of nuclear material and the division of the cell. Dr. G. W. Kidder (Amherst College, Massachusetts) gave an account of the effect of folic acid analogues upon the growth of Tetrahymiena, a ciliated protozoon possessing an absolute dietary requirement for folic acid. The multiplication of this organism is inhibited by folic acid analogues in which substitutions have been made on the ring systems, the inhibition of growth being reversed by folic acid, but not by any combination of purines and pyrimidines. The organism cannot utilize folic acid analogues in which the glutamic acid residue has been replaced by another amino-acid, indicating that it cannot hydrolyse the bond between the $p$-aminobenzoic acid portion of the molecule and the amino-acid residue.

Dr. W. Jacobson described the accumulation of cells at the metaphase stage of division in the bone marrow of lexkæmic patients or leukæmic mice treated with folic acid antagonists. The inhibition of cell division is reversed by the citrovorum factor, but not by pteroylglutamic acid, demonstrating that the cells cannot utilize or convert pteroylglutamic acid itself. Accordingly, it seems that folic acid antagonists replace the citrovorum factor within the dividing cells, and that the citrovorum factor performs a vitally important function during the few minutes of the transition from the metaphase to anaphase stages of mitosis. Similar biological effects of the folic acid antagonists were reported by Dr. R. Bellairs (University College, London) with reference to the embryonie development of the chick. The treatment of chick embryos with aminopterin or amethopterin during gastrulation brings about a clumping of the chromosomes at the metaphase stage of cell division, and leads to a retarded, abnormal growth which is manifest notably in a failure of the neural plate to close dorsally and of the foregut floor to close off ventrally. Normal embryogeny is observed when the citrovorum factor is injected simultaneously with the folic acid antagonist, but not when pteroylglutamic acid is injected with the antagonist.

Prof. A. Haddow (Chester Beatty Research Institute, London) reported that xanthopterin brings about a marked increase in the size of the kidney of the rat, an increase caused by a greatly increased rate of mitosis leading to excessive but perfectly normal cell-division in the kidney tubules. Dr. 
Jacobson described a yellow pigment, isolated from the argentaffine cells of the mammalian intestinal mucosa, which possesses a fluorescence spectrum strikingly similar to that of xanthopterin in regard to both the position and the intensity of the bands. Accordingly, it is of some interest that the argentaffine cells have been found to be much reduced in number in certain types of megaloblastic anæmias. Comparing the incidence of megaloblastic anæmia in India and Britain, Dr. R. H. Girdwood (Medical Department, University of Edinburgh) related the higher incidence of the disease in India to the lower folic acid content of the average Indian diet. How ever, the relation between the disease and folic acid deficiency is not a simple one, for it is possible to have cases of megaloblastic anæmia associated with intestinal malabsorption of folic acid, without vitamin $B_{12}$ depletion, and yet have a normal excretion of folic acid after the injection of a test dose of pteroylglutamic acid. With reference to this problem, Dr. E. M. Coates (National Institute for Research in Dairying, Reading) reported that vitamin $B_{12}$ does not alleviate folic acid deficiency in chicks, nor does folic acid reduce the vitamin $B_{12}$ requirements of the chick.

Dr. J. Colsky (Maimonides Hospital of Brooklyn, New York) gave an account of the case histories of several leukæmic patients treated with folic acid antagonists. Continuous treatment with the antagonists over a period of months was accompanied, in five out of six cases, by a disturbance of the liver functions, which resulted ultimately in severe fibrosis of the liver. Dr. Colsky suggested that the production of a folic acid deficient state by means of the antagonists may cause injury to the liver by interference with the normal metabolism of choline, methionine and betaine.

In opening the symposium, Prof. Albert paid a tribute to the discoverer of the natural pteridines, Gowland Hopkins, whose work was also appraised by Dr. Jacobson at the end of the final session in a general review of the progress achieved in the pteridine field. At the close of the symposium the members expressed their appreciation of the work of the director of the Ciba Foundation, Dr. G. E. W. Wolstenholme, and of his staff, who, by their efficient organization, had materially contributed to the success of the conference.

S. F. MASON

\section{PLEISTOCENE GEOLOGY OF BRITAIN}

$\mathrm{D}$ ATA of a novel and curious kind provide, in the words of Mr. R. G. Carruthers, an interpretation of the British boulder clay deposits which differs radically from that hitherto current. 'The 'orthodox' scheme, with its multiglaciation and interglacials, is disregarded altogether in a booklet entitled "Glacial Drifts and the Undermelt Theory"'. Instead, all the British tills and many of the accompanying glacifluvial deposits are explained as an "undermelt" product of one great glaciation, and "changes of some moment are suggested in the conventional North European scheme, which brings a long-sought harmony into its relations with the Alps on one hand and Britain on the other".

This contribution of Carruthers to Pleistocene geology is remarkable in several respects. Not only does it do away with the views developed by other authors and proposes a new scheme of correlation between northern France, the Thames, East Anglia, Denmark, north Germany and the Alps, but also it raises a serious question of scientific method, which deserves to be noted here.

Relying on certain observations of the effects of subglacial melting, the author develops his 'undermelt theory'. Subglacial melting and shear-structures have for many years been known from the Scandinavian area of glaciation, though Carruthers was probably the first to note some of them in Britain. Moreover, he undertook to explain many other observations by means of this same phenomenon ${ }^{2}$, and he eventually convinced himself that the various sheets of moraine in Crreat Britain all belong to the same glaciation. In doing so, he applied the interpretation he gave to a small set of observations to a very wide field (now including the whole of the formerly glaciated part of Britain) and he was happy to find that the sequence of Pleistocene deposits appeared much simpler if monoglaciation was adopted. Multiglaciation is attacked by saying that in Britain the sequence can be interpreted monoglacially. With this most workers in the field of Pleistocene geology are compelled to disagree, for reasons that are not mentioned by Carruthers and, judging from the list of references, were perhaps not known to him.

But granting that this 'undermelt theory' is possible, there remains to be assessed its degree of probability. This Carruthers does not do. The new 'possible' interpretation of the sequence of tills is, without any discussion of the conclusions of earlier authors, regarded as probable, nay, even as the only sound one. In regarding the possible as probable, Carruthers does not stand alone. It is a tendency of many scientific writers, which must be regarded as decidedly harmful. The valuable work of earlier authors which led to different conclusions is not refuted, but simply remains unconsidered, and the new theory can thus be made to appear in a spotless garb. Readers who are not themselves experts in the field will thus be misled into believing that the theory proposed is the only one worthy of consideration. From the point of view of scientific method this is a deplorable way of presenting scientific interpretations ; scientists should discuss in their publications the reasons for considering their own hypothesis or theory more probable than others previously put forward.

When Carruthers undertakes to fit his British monoglacialism in with the Continental chronology, he finds "at long last, ... re-advances and interglacial periods proved beyond a shadow of doubt". It appears that it did not occur to him that this multiglacialism of the countries from France to Denmark, the nearest neighbours of Britain, renders his British monoglacialism improbable. He goes to some length in determining the age of the Eem Sea. 'This effort is considerably out of date, the latest publication quoted being more than twenty years old, while several treatises in English, French and German are available from which the necessary information might have been obtained ${ }^{3}$. A chronological scheme is thus developed which only the uninitiated might be prepared to consider. The four glaciations (Elster, Saale, Warthe, Weichsel) are considered separated by three interglacials, the first being represented by the Holstein clays, the middle interglacial by the Eem, and the last interglacial by the Brasenia Beds. While the Holstein Sea is now generally placed between Elster and Saale, it is the 